\title{
Beyond Cockpit-ism: Four Insights to Enhance the Transformative Potential of the Sustainable Development Goals
}

\author{
Maarten Hajer ${ }^{1,2, *}$, Måns Nilsson ${ }^{3,4}$, Kate Raworth ${ }^{5}$, Peter Bakker ${ }^{6}$, Frans Berkhout ${ }^{7}$, \\ Yvo de Boer ${ }^{8}$, Johan Rockström ${ }^{9}$, Kathrin Ludwig ${ }^{1}$ and Marcel Kok ${ }^{1, *}$
}

1 PBL Netherlands Environmental Assessment Agency, P.O. Box 30314, 2500 GH The Hague, The Netherlands; E-Mail: kathrin.ludwig@pbl.nl

2 University of Amsterdam, Department of Political Science, OZ Achterburgwal 237, 1012 DL Amsterdam, The Netherlands

3 Stockholm Environment Institute, Linnégatan 87 D, Stockholm 115 23, Sweden; E-Mail: mans.nilsson@sei-international.org

4 KTH Royal Institute of Technology, Drottning Kristinas Väg 30, Stockholm 100 44, Sweden

5 Environmental Change Institute, Oxford University, Oxford OX1 3QY, UK; E-Mail: kate.raworth@ouce.ox.ac.uk

6 World Business Council for Sustainable Development, Chemin Eugène-Rigot 2, 1211 Geneva, Switzerland; E-Mail: bakker@wbcsd.org

7 Future Earth, c/o International Council for Science (ICSU), 5 Rue Auguste Vacquerie, 75116 Paris, France; E-Mail: frans.berkhout@kcl.ac.uk

8 Global Green Growth Institute, 19F Jeongdong Bldg., 21-15 Jeongdong-gil, Jung-gu Seoul 100-784, Korea; E-Mail: yvo.deboer@gggi.org

9 Stockholm Resilience Center, Stockholm University, SE-106 91 Stockholm, Sweden; E-Mail: johan.rockstrom@su.se

* Authors to whom correspondence should be addressed; E-Mails: maarten.hajer@pbl.nl (M.H.); marcel.kok@pbl.nl (M.K.); Tel.: +31-70-3288-730 (M.H.); +31-6-11045098 (M.K.).

Academic Editor: Vincenzo Torretta

Received: 24 December 2014 / Accepted: 28 January 2015 / Published: 4 February 2015

\begin{abstract}
The Sustainable Development Goals (SDG) have the potential to become a powerful political vision that can support the urgently needed global transition to a shared and lasting prosperity. In December 2014, the United Nations (UN) Secretary General published his report on the SDGs. However, the final goals and targets that will be adopted by the UN General Assembly in September 2015 risk falling short of expectations because
\end{abstract}


of what we call "cockpit-ism": the illusion that top-down steering by governments and intergovernmental organizations alone can address global problems. In view of the limited effectiveness of intergovernmental efforts and questions about the capacity of national governments to affect change, the SDGs need to additionally mobilize new agents of change such as businesses, cities and civil society. To galvanize such a broad set of actors, multiple perspectives on sustainable development are needed that respond to the various motives and logics of change of these different actors. We propose four connected perspectives which can strengthen the universal relevance of the SDGs: "planetary boundaries" to stress the urgency of addressing environmental concerns and to target governments to take responsibility for (global) public goods; "the safe and just operating space" to highlight the interconnectedness of social and environmental concerns and its distributive consequences; "the energetic society" to benefit from the willingness of a broad group of actors worldwide to take action; and "green competition" to stimulate innovation and new business practices. To realize the transformative potential of the SDGs, these four perspectives should be reflected in the focus and content of the SDGs that will be negotiated in the run up to September 2015 and its further implementation.

Keywords: sustainable development goals; post-2015 agenda; planetary boundaries; safe and just operating space; energetic society; agents of change; cockpit-ism

\section{Introduction}

The decision to craft a set of Sustainable Development Goals (SDGs) is widely regarded as the most tangible result of the 2012 United Nations (UN) Rio+20 Conference on sustainable development. The SDGs have the potential to function as a guiding star for galvanizing action at multiple scales for a shared and lasting prosperity. The SDGs also constitute an important opportunity to move beyond the development agenda of the Millennium Development Goals (MDG) towards a universally relevant agenda that integrates social, economic and environmental goals, and includes targets for both developed and developing countries. The Open Working Group (OWG) on Sustainable Development Goals has proposed a set of 17 goals and 169 targets [1]. These goals and targets are the basis for the formal negotiations that should result in the adoption of the SDGs by the UN General Assembly in September 2015. Recently, UN Secretary General Ban Ki Moon issued a Synthesis Report on the post-2015 agenda which endorses the work of the OWG [2]. However, the formulation and implementation of the final goals and targets risk falling short of expectations because of what we call "cockpit-ism": the illusion that top-down steering by governments and intergovernmental organizations alone can address global problems.

Summits like Rio+20 are highlights in global processes-gatherings of national leaders that symbolically function as a "cockpit" from which international policy directions are formulated in a top-down logic of steering. Although global environmental diplomacy has led to the creation of hundreds of multilateral environmental agreements, including the well-known conventions and protocols 
on climate change, desertification and biodiversity, these agreements have been criticized for their limited effectiveness in solving the very problems they were designed to address [3-5].

While reaching agreement in the UN with almost 200 countries is always going to be difficult, the steering capacity of the intergovernmental system is increasingly out of sync with expectations and demands of citizens, civil society and business. At Rio+20, policy makers and scientists called for a constitutional moment to improve global governance [6]. The business community demanded government action and rapidly growing countries from the South made their presence felt, recasting the geopolitical power balance underpinning multilateral policymaking.

In view of the limited success of environmental governance, the SDGs need to target not only governments, but other agents of change such as businesses, cities, citizens and civil society. Key documents of the SDG process such as the Rio+20's The Future We Want, the OWG's draft proposal and the Secretary General's recent Synthesis Report do refer to the importance of "the active involvement of all relevant stakeholders" [1,2,7]. However, these preparatory documents address business, cities and civil society only to a limited extent. Especially with respect to environmental concerns, the SDGs could address other agents of change much more directly.

For the post-2015 agenda to open up a new chapter in global governance, sustainable development needs to be reframed. SDGs that reflect diverse perspectives on sustainable development can help mobilize a broader coalition of actors and thereby enhance the universal relevance of the SDGs. For this purpose, we suggest four connected perspectives that address both governments and other agents of change: "planetary boundaries" to strengthen the urgency of addressing environmental concerns and to target governments; "the safe and just operating space" to highlight the interconnectedness of social and environmental concerns; "the energetic society" to build on the broader societal willingness to take action; and "green competition" to stimulate innovation and new business practices. These four perspectives are neither entirely novel nor entirely separable. Yet, they can help embed the SDGs in the policies and practices of society and business at large by reorienting the debate and responding to the various motives and logics of change that characterize these agents of change. Furthermore, these perspectives link and support the six "essential elements" of the Secretary General's Synthesis Report: dignity, people, prosperity, planet, justice and partnership [2].

\section{Planetary Boundaries}

Three years before the Rio+20 Summit in 2012, Rockström et al., drew the attention of policy-makers to nine planetary boundaries [8]. In the tradition of The Limits to Growth report, these boundaries mark precautionary limits for critical Earth system processes that regulate the stability of the planet [9]. Planetary boundaries demarcate a "safe operating space" "for humanity" on Earth. For issues such as climate change, biodiversity loss, chemical pollution, and altered nutrient cycles, the rate and scale of human perturbation are a global concern, not just a local one. Transgressing these boundaries presents rising risks of threshold changes and risks for people and planet. In the 2015 follow-up paper, Steffen, et al. [10] revised and updated the analysis of the planetary boundaries and examined how transgressing five of the nine planetary boundaries at the sub-global level affects the Earth system as a whole showing the importance of cross-scale interactions. 
To ensure that the SDG framework will be more than the (much needed) extension of the current MDG agenda to 2030, the environmental preconditions for human development need to be recognized in goals and targets [11]. However, environmental sustainability is inconsistently covered in the framework of SDG goals that have emerged from political negotiations so far. Environmental concerns are less often named in goals, less well-defined and more often addressed in targets under goals focused on the social and economic dimensions of sustainable development [12]. For example, the proposed targets for halting biodiversity loss and combating climate change do not have target dates. For other environmental concerns it remains unclear when a target would be considered as achieved. With its focus on the environmental preconditions for sustainable development, the planetary boundaries perspective can strengthen the focus on environmental concerns.

The planetary boundaries framework received considerable attention in the multilateral policy-making arena before and after Rio+20. Framing the environmental dimension of sustainable development in terms of boundaries works well to raise awareness and is critical to understand the need for a transition to a development paradigm with agreed global sustainability targets [11]. However, planetary boundaries only address the environmental preconditions of human development (e.g., by setting a global carbon, nitrogen and phosphorus budget within which humanity can evolve safely). Furthermore, "planetary boundaries" and "humanity" are concepts from a language of universals which does not speak to the differentiated interests, concerns and capabilities of people. It appeals to an overarching concern which, however, can help to mobilize governments to take action. Planetary boundaries can guide governments in formulating environmental policy strategies. For instance, Sweden and Switzerland are already using planetary boundaries as guiding principles in their national environmental policies. Germany has recently commissioned research on how to apply the concept nationally.

While planetary boundaries emphasize the urgency of environmental problems, the concept does not address the distributional issues and opportunities linked to access to environmental resources and services which are central to reaching consensus at the international level. To galvanize action around the SDGs, the environmental focus of planetary boundaries needs to be complemented with development perspectives that correspond to the motives and logics of change of society and business at large.

\section{Safe and Just Operating Space}

The notion of a "safe and just operating space" adds social concerns to planetary boundaries, represented in a doughnut-shaped "safe and just space for humanity" (see Figure 1) [13]. We are currently operating outside both sets of boundaries, facing both human deprivation and environmental degradation: moving into the "safe and just space" will demand both far greater efficiency in resource use for meeting human needs, and far greater equity in its global distribution.

The starting point here is that whenever there are resource constraints, there is always the question-spoken or not- of how available resources are socially distributed, internationally, nationally and locally. Adding social boundaries to the conceptualization of planetary boundaries makes this explicit, asserting the claim of every person to the resources they need to achieve an essential "social foundation". This equity-based logic for action addresses concerns of developing countries with respect to responsibilities and resource distribution. The global resource challenge shifts 
from being a matter of "living within limits" to one of "living in balance" between social and environmental boundaries that together establish the necessary conditions for human wellbeing.

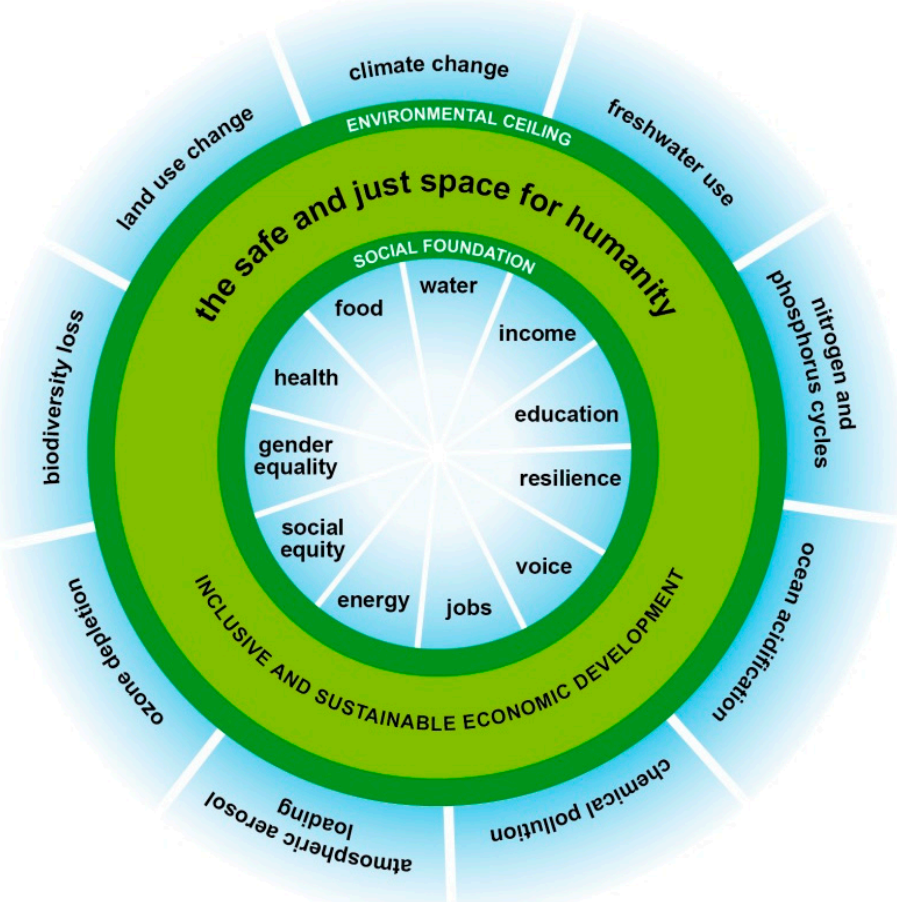

Figure 1. The Doughnut of Social and Planetary Boundaries. Source: [13].

The social dimension of the "safe and just operating space" has received considerable attention in the development of SDG goals and targets, while environmental concerns have been formulated in a less clear language. SDGs seen through the lens of the "safe and just operating space" highlights the responsibilities and rights of both developing and developed countries and links to the principle of common but differentiated responsibilities in international negotiations. Reflecting the interconnectedness of social and environmental concerns in the SDGs will strengthen their universal relevance. To ensure such universal relevance, much work remains to operationalize SDGs in the different development contexts of countries. One way of operationalizing the SDGs to country [14] or regional levels is to take such a regional approach to the "safe and just operating space" by focusing "on the links between social wellbeing (e.g., food security) and the sustainable management of resources (e.g., sustainable fish farming) within a particular region" [15]. For South Africa, for instance, a national barometer was developed that downscaled the safe and just operating space, combining 20 indicators and boundaries for environmental stress and social deprivation [16].

\section{Energetic Society}

In a multipolar, multi-actor world, governments can draw on and collaborate with societal actors as agents of change to develop responses to environmental change. We have long moved out of the era of "classical-modernist" governance through governments. However, environmental diplomacy is only slowly recognizing the consequences of this shift, and still grapples with understanding its implications $[17,18]$. 
An "energetic society" perspective highlights the transformative potential of the multiple initiatives for sustainable development taken by various agents of change within societies around the world [19]. Such actors are articulate, autonomous citizens, civil society initiatives, self-organized farmers, cities and innovative companies that take action in highly diverse development contexts. Different logics of change are at play: actors may be motivated by a genuine concern for sustainability, or by new opportunities arising from sustainability challenges. While in many countries, governments are retreating from the direct provision of public goods [20], the energetic society steps in and provides public services ranging from the creation of more green areas through local energy provision to the provision of knowledge and information, for instance through citizen science. At the same time, these agents of change often do not find sufficient support from international and national policies. National governments are still in a learning process of how to most fruitfully facilitate and engage with the energetic society. Such an engagement would require governments to remove regulations that undermine efforts for sustainability and provide an enabling and regulatory framework that supports the actions new agents of change are taking in an energetic society. For instance, governments can provide sustainable infrastructure through smart grids and smart meters or develop innovation-oriented and dynamic regulation [19].

SDGs formulated in a way that speaks to this broad group of change agents would help governments to unleash societal energy and will provide guidance for societal actors to adopt more sustainable strategies and practices. Instead of targeting national cockpits, the SDGs therefore need to challenge positively new agents of change to take action in their own fields of concern or expertise. The SDG preparatory documents mainly address governments, and to a lesser extent, cities and businesses. Citizens, consumers and civil society are not actively targeted. Citizens are targeted via governments ("ensure that people everywhere have the relevant information and awareness for sustainable development and lifestyles in harmony with nature"), but they are not called to take action themselves [1].

In the SDG preparatory documents, the crucial role of cities is addressed in a standalone goal with targets for housing, transport, adaptation at the city-level and reduction of the per capita environmental impact of cities. Yet, the formulation of the target on reducing cities' environmental impacts focuses especially on air quality and waste management. This leaves out the opportunity to encourage cities to become arenas for public-private and social innovations leading to transformative change in resource efficiency and environmental quality. Other important aspects at play at the city level are food security and the provision of clean water. These are addressed in goals 2 and 6 of the OWG's draft. Yet, specifying targets on food and clean water provision for the city level would reinforce the urgency for cities to take action and cater to the basic needs of their citizens.

\section{Green Competition}

For business, competition, innovation and market opportunities are important motives for transitioning to more sustainable practices. The SDGs need to connect to the logic of the business and finance community, and mobilize and engage them as agents of change. This requires toning down the narrative of limits and emphasizing the narrative of opportunities. Socio-technical innovations are 
fundamental to staying within a "safe and just operating space" by opening up new business opportunities and fostering radically new ways of delivering goods, services and well-being [21].

Motivated by first mover advantages, reducing global supply chain risks, capturing efficiency gains and changing corporate norms and values, sustainability has come to the strategic core of many leading businesses [22]. Recent examples of business engagement with innovation and risk management in response to sustainability challenges are the Integrated Reporting Initiative that advocates integrated sustainability and financial reporting, Action 2020 by the World Business Council for Sustainable Development or the initiative Risky Business which assesses the economic risks of climate change in the United States. Broader discursive efforts in the "green competition" perspective are found in the Inclusive Green Growth agenda and the recent New Climate Economy initiative chaired by former Mexican President Felipe Calderón. These are first steps. Yet, for existing efforts to add up, companies in business and finance need to move further and faster. Here, governments have a clear role in setting the right incentives and for good practices consistent with SDG goals and targets, and dis-incentivizing unsustainable systems and practices.

The SDGs can guide "green competition" for novel ideas and technologies at the macro scale and stimulate new business practices. Technology is addressed in the goal on the Means of Implementation (targets 17.6. to 17.8) of the OWG's draft SDGs, mainly focusing on knowledge transfer [1]. This framing of the technology problem — as being concerned primarily with access to leading technologies in developing countries-ignores the more fundamental problem, which is the need to stimulate transformative "systems innovation" across economies and societies, as one of the conditions of sustainability [23]. Further, the SDG preparatory documents propose a target on sustainable corporate practices and on corporate (and integrated) reporting. Such a target (12.6 in the OWG's draft) can gain salience through strong indicators. Such indicators could be the number and quality of sustainability standards adopted and national legislations passed that makes integrated reporting and sustainable sourcing practices mandatory. Business plays a key role in sustainable development and needs to be held more directly accountable. Targets on sustainable production and resource efficiency that directly address businesses will not only support front runners in developing sustainable business models but will also put pressure on laggards to change unsustainable corporate practices.

\section{Conclusions}

The SDGs have the potential to become the guiding vision for governmental, corporate and civil society action for a shared and lasting prosperity. To avoid becoming an MDG+ agenda and instead provide a long-term and universally relevant vision, the SDGs need to move beyond a focus on the cockpit, and reflect the four perspectives discussed in this paper. The SDGs need to inspire and challenge multiple agents of change including governments: "planetary boundaries" to strengthen the urgency of addressing environmental concerns, "the safe and just operating space" to highlight the interconnectedness of social and environmental concerns and its distributive consequences for industrialized countries and emerging economies, "the energetic society" to engage new agents of change to forge ahead with new, more sustainable ways of doing things, and "green competition" to initiate novel ideas and technologies and stimulate new business practices. To realize the 
transformative potential of the SDGs, these four perspectives should be reflected more strongly in the focus and content of the SDGs that will be negotiated in the course of 2015.

Recognizing the constraints of cockpit-ism, we need to consciously target the SDGs to align with agents of change from business, civil society, and cities around the world. The four perspectives outlined in this article can strengthen the link between these actors and in doing so, support the universal relevance of the SDGs. In his December 2014 Synthesis Report, Secretary General Ban Ki Moon proposes multi-stakeholder peer reviews of national progress that includes contributions from non-governmental stakeholders "based upon globally-harmonized formats" [2]. This is a step in the right direction to more strongly engage new agents of change. A combination of perspectives on sustainable development can further help mobilize this broader set of actors, build partnerships and contribute to a better understanding of the synergies and tensions inherent to alternative pathways to sustainable development. National governments and multilateral organizations will need to rethink the role they play in achieving this. With the four perspectives reflected in the SDG framework, sustainable development has more potential than ever to become an influential and transformative norm in the 21 st century.

\section{Acknowledgments}

We would like to thank Paul Lucas (PBL), Sarah Cornell (SRC) and two anonymous reviewers for their insightful comments and suggestions.

\section{Author Contributions}

Maarten Hajer, Marcel Kok and Kathrin Ludwig designed the paper, and with Måns Nilsson and Kate Raworth developed and wrote the first draft of the paper, that was further completed with invited contributions from Peter Bakker, Frans Berkhout, Yvo de Boer and Johan Rockström. All authors read and approved the final manuscript.

\section{Conflicts of Interest}

The authors declare no conflict of interest.

\section{References}

1. United Nations General Assembly. Open Working Group Proposal for Sustainable Development Goals (A/68/970); United Nations: New York, NY, USA, 2014.

2. United Nations. The Road to Dignity by 2030: Ending Poverty, Transforming All Lives and Protecting the Planet; United Nations: New York, NY, USA, 2014.

3. Prins, G.; Rayner, S. Time to ditch Kyoto. Nature 2007, 449, 973-975.

4. Elliott, L. The United Nations' Record on Environmental Governance: An assessment. In A World Environment Organization: Solution or Threat for Effective International Environmental Governance? Biermann, F., Bauer, S., Eds.; Ashgate: Aldershot, UK, 2005; pp. 27-56.

5. Newell, P. A World Environmental Organisation: The Wrong Solution to the Wrong Problem. World Econ. 2002, 25, 659-671. 
6. Biermann, F.; Abbott, K.; Andresen, S.; Bäckstrand, K.; Bernstein, S.; Betsill, M.M.; Bulkeley, H.; Cashore, B.; Clapp, J.; Folke, C.; et al. Navigating the Anthropocene: Improving Earth System Governance. Science 2012, 335, 1306-1307.

7. United Nations General Assembly. The Future We Want (A/RES/66/288); United Nations: New York, NY, USA, 2012.

8. Rockström, J.; Steffen, W.; Noone, K.; Persson, Å.; Chapin, F.S.; Lambin, E.F.; Lenton, T.M.; Scheffer, M.; Folke, C.; Schellnhuber, H.J.; et al. A Safe Operating Space for Humanity. Nature 2009, 461, 472-475.

9. Meadows, D.H.; Goldsmith, E.I.; Meadow, P. The Limits to Growth; Earth Island Limited: London, UK, 1972; Volume 381.

10. Steffen, W.; Richardson, K.; Rockström, J.; Cornell, S.E.; Fetzer, I.; Bennett, E.M.; Biggs, R.; Carpenter, S.R.; de Vries, W.; de Wit, C.A. Planetary boundaries: Guiding human development on a changing planet. Science 2015, doi: 10.1126/science.1259855.

11. Griggs, D.; Stafford-Smith, M.; Gaffney, O.; Rockström, J.; Ohman, M.C.; Shyamsundar, P.; Steffen, W.; Glaser, G.; Kanie, N.; Noble, I. Policy: Sustainable Development Goals for People and Planet. Nature 2013, 495, 305-307.

12. Raworth, K. Will these Sustainable Development Goals Get us into the Doughnut? In From Poverty to Power; Green, D., Ed.; Oxfam: Oxford, UK, 2014; Volume 2014.

13. Raworth, K. A Safe and Just Space for Humanity: Can We Live within the Doughnut? Oxfam: Oxford, UK, 2012.

14. Nykvist, B.; Persson, Å.; Moberg, F.; Persson, L.; Cornell, S.; Rockström, J. National Environmental Performance on Planetary Boundaries. In Swedish Environmental Protection Agency Report 6576; Swedish Environmental Protection Agency: Stockholm, Sweden, 2013.

15. Dearing, J.A.; Wang, R.; Zhang, K.; Dyke, J.G.; Haberl, H.; Hossain, M.S.; Langdon, P.G.; Lenton, T.M.; Raworth, K.; Brown, S.; et al. Safe and just operating spaces for regional social-ecological systems. Glob. Environ. Chang. 2014, 28, 227-238.

16. Cole, M.J.; Bailey, R.M.; New, M.G. Tracking sustainable development with a national barometer for South Africa using a downscaled "safe and just space" framework. Proc. Natl. Acad. Sci. USA 2014, 111, E4399-E4408.

17. Rosenau, J.N.; Czempiel, E.-O. Governance without Government: Order and Change in World Politics; Cambridge University Press: Cambridge, UK, 1992; Volume 20.

18. Hajer, M.A. Authoritative Governance: Policy Making in the Age of Mediatization; Oxford University Press: Oxford, UK, 2009.

19. Hajer, M.A. The Energetic Society. In Search of a Governance Philosophy for a Clean Economy; PBL Netherlands Environmental Assessment Agency: The Hague, The Netherlands, 2011.

20. Strange, S. The Retreat of the State: The Diffusion of Power in the World Economy; Cambridge University Press: Cambridge, UK, 1996.

21. World Business Council for Sustainable Development. WBCSD Submission of Climate Change Business Solutions to the United Nations Climate Summit; WBCSD: Geneva, Switzerland, 2014.

22. Pattberg, P. How Climate Change Became a Business Risk: Analyzing Nonstate Agency in Global Climate Politics. Environ. Plan. C Gov. Policy 2012, 30, 613-626. 
23. Elzen, B.; Geels, F.W.; Green, K. System Innovation and the Transition to Sustainability: Theory, Evidence and Policy; Edward Elgar Publishing: Cheltenham, UK, 2005.

(C) 2015 by the authors; licensee MDPI, Basel, Switzerland. This article is an open access article distributed under the terms and conditions of the Creative Commons Attribution license (http://creativecommons.org/licenses/by/4.0/). 